Article

\title{
Genome-Wide Characterization of Sedum plumbizincicola HMA Gene Family Provides Functional Implications in Cadmium Response
}

\author{
Qingyu Huang 1,2,3, ${ }^{\text {, Wenmin Qiu }}{ }^{2,3,+}$, Miao Yu ${ }^{2}$, Shaocui Li $^{2}$, Zhuchou Lu ${ }^{2}$, Yue Zhu ${ }^{2}$, Xianzhao Kan ${ }^{1, * \mathbb{D}}$ \\ and Renying Zhuo $2,3, *$
}

check for updates

Citation: Huang, Q.; Qiu, W.; Yu, M.; Li, S.; Lu, Z.; Zhu, Y.; Kan, X.; Zhuo, R. Genome-Wide Characterization of Sedum plumbizincicola HMA Gene Family Provides Functional Implications in Cadmium Response. Plants 2022, 11, 215. https://doi.org/ $10.3390 /$ plants 11020215

Academic Editor: Adnane Boualem

Received: 23 December 2021

Accepted: 12 January 2022

Published: 14 January 2022

Publisher's Note: MDPI stays neutral with regard to jurisdictional claims in published maps and institutional affiliations.

Copyright: (c) 2022 by the authors Licensee MDPI, Basel, Switzerland. This article is an open access article distributed under the terms and conditions of the Creative Commons Attribution (CC BY) license (https:// creativecommons.org/licenses/by/ $4.0 /)$.
1 The Institute of Bioinformatics, College of Life Sciences, Anhui Normal University, Wuhu 241000, China; hqy1108@ahnu.edu.cn

2 State Key Laboratory of Tree Genetics and Breeding, Chinese Academy of Forestry, Beijing 100091, China; qiuwm05@caf.ac.cn (W.Q.); myu@caf.ac.cn (M.Y.); lishaocui@caf.ac.cn (S.L.); luzc@caf.ac.cn (Z.L.); zhuyue1992@caf.ac.cn (Y.Z.)

3 Key Laboratory of Tree Breeding of Zhejiang Province, The Research Institute of Subtropical Forestry, Chinese Academy of Forestry, Hangzhou 311400, China

* Correspondence: xianzhao@ahnu.edu.cn (X.K.); zhuory@caf.edu.cn (R.Z.); Tel.: +86-139-5537-2268 (X.K.); +86-0571-63311860 (R.Z.)

$+\quad$ These authors contributed equally to the work.

\begin{abstract}
Heavy-metal ATPase (HMA), an ancient family of transition metal pumps, plays important roles in the transmembrane transport of transition metals such as $\mathrm{Cu}, \mathrm{Zn}, \mathrm{Cd}$, and $\mathrm{Co}$. Although characterization of HMAs has been conducted in several plants, scarcely knowledge was revealed in Sedum plumbizincicola, a type of cadmium (Cd) hyperaccumulator found in Zhejiang, China. In this study, we first carried out research on genome-wide analysis of the HMA gene family in S. plumbizincicola and finally identified 8 SpHMA genes and divided them into two subfamilies according to sequence alignment and phylogenetic analysis. In addition, a structural analysis showed that $S p H M A$ s were relatively conserved during evolution. All of the SpHMAs contained the HMA domain and the highly conserved motifs, such as DKTGT, GDGxNDxP, PxxK S/TGE, HP, and $\mathrm{CPx} / \mathrm{SPC}$. A promoter analysis showed that the majority of the $\mathrm{S} P H M A$ genes had cis-acting elements related to the abiotic stress response. The expression profiles showed that most SpHMAs exhibited tissue expression specificity and their expression can be regulated by different heavy metal stress. The members of $\mathrm{Zn} / \mathrm{Co} / \mathrm{Cd} / \mathrm{Pb}$ subgroup (SpHMA1-3) were verified to be upregulated in various tissues when exposed to $\mathrm{CdCl}_{2}$. Here we also found that the expression of $S p H M A 7$, which belonged to the $\mathrm{Cu} / \mathrm{Ag}$ subgroup, had an upregulated trend in Cd stress. Overexpression of SpHMA7 in transgenic yeast indicated an improved sensitivity to $\mathrm{Cd}$. These results provide insights into the evolutionary processes and potential functions of the HMA gene family in S. plumbizincicola, laying a theoretical basis for further studies on figuring out their roles in regulating plant responses to biotic/abiotic stresses.
\end{abstract}

Keywords: HMA family genes; Sedum plumbizincicola; evolution; nutrient deficiency; divalent metal toxicity; expression profiles; SpHMA7

\section{Introduction}

The rapid development of modern industry, agriculture and urbanization has increased heavy metal contamination [1]. Both essential heavy metals [2] such as cuprum $(\mathrm{Cu})$, zinc $(\mathrm{Zn})$, and manganese $(\mathrm{Mn})$, and some nonessential metals such as cadmium $(\mathrm{Cd})$ can be absorbed by plants. However, excessive accumulation of nonessential heavy metals can produce toxic effects on plants and their toxicity is a problem of increasing significance for they can enter the food chain and finally have a serious impact on the human or environmental system [3-5]. To reduce the risks for humans and create a better living environment, 
soil heavy metal remediation technology has become a research hotspot, among which phytoremediation is widely regarded to have a great prospect [6-8].

For the moment, there are more than 720 species of angiosperms have been identified as heavy metal hyperaccumulators, most of which are nickel (Ni) hyperaccumulators [9]. There are about ten kinds of plants that have been identified as Cd hyperaccumulators, among which Sedum plumbizincicola, which is found in a lead-zinc mine in Zhejiang, China, has been extensively studied [10-14]. Normally, Cd hyperaccumulator refers to the accumulation of $\mathrm{Cd}$ in the above-ground tissues of the plant at least $100 \mathrm{mg} / \mathrm{kg}$ [15], while the accumulation of $\mathrm{Cd}$ in the above-ground part of $S$. plumbizincicola can exceed $7000 \mathrm{mg} / \mathrm{kg}$ without showing symptoms of poisoning [16,17]. In addition, it was also found that S. plumbizincicola has a strong Cd transport capacity [18]. At present, researchers have carried out many years of indoor and outdoor experimental research, conducted large-scale farmland restoration experiments and achieved good results. At the same time, they also established the incineration technology of plants containing toxic heavy metals. However, S. plumbizincicola, as an herbaceous plant, has the limitation of low biomass. Therefore, it is of great significance to study the molecular mechanism of high $\mathrm{Cd}$ tolerance and enrichment of S. plumbizincicola.

Plants have developed a set of basic strategies to respond to metalliferous soils during their growth and development [19]. It mainly includes the accumulation and transport of heavy metals [20]. Accumulation occurs mainly in the roots and there is a certain limit to the amount of accumulation while transport can realize the absorption and transport of many cations from the root to the shoot and redistribution among aerial parts [21]. Transporters play important roles in these processes. Studies have identified such metal transporters as Zn-regulated transporter-like protein (ZNT/ZIP), metal tolerance protein $(\mathrm{MTP})$, natural resistance associated macrophage protein (NRAMP), heavy-metal ATPase $(H M A)$, and ATP-binding cassette $(\mathrm{ABC})$ to participate in metal transportation [22]. Among these transporters, heavy-metal ATPase (HMA), also known as $\mathrm{P}_{1 \mathrm{~B}}$-type ATPase, belongs to the P-type ATPase superfamily, a large group of enzymes that can pump a wide range of cations across membranes against their electrochemical with the energy resulting from ATP hydrolysis [23]. Structurally, the HMAs usually contain 6-8 transmembrane helices, a CPx/SPC motif in transmembrane domain six and metal-binding domains in the $\mathrm{N}$ terminal and $\mathrm{C}$-terminal regions that can bind and interact with specific metal ions, such as $\mathrm{Cd}^{2+}$ and $\mathrm{Pb}^{2+}$. HMAs can be divided into two groups by the substrate specificity, namely, the $\mathrm{Cu} / \mathrm{Ag}$-ATPases group and $\mathrm{Zn} / \mathrm{Co} / \mathrm{Cd} / \mathrm{Pb}$-ATPases group [24,25]. The physiological functions of HMAs were revealed at the genomic scale in Arabidopsis thaliana and Oryza sativa. There are $8 \mathrm{HMAs}$ in A. thaliana and 9 in $O$. sativa respectively, among which, AtHMA1-4 and OsHMA1-3 belong to the $\mathrm{Cu} / \mathrm{Ag}$ subgroup, and AtHMA5-8 and OsHMA4-9 belong to the $\mathrm{Zn} / \mathrm{Co} / \mathrm{Cd} / \mathrm{Pb}$ subgroup [26]. In A. thaliana, AtHMA1 localizes to the chloroplast envelope and is involved in exporting $\mathrm{Zn}$ from the chloroplast [27]. Overexpression of $A t H M A 3$ enhances tolerance and accumulation of $\mathrm{Cd}, \mathrm{Zn}, \mathrm{Pb}$, and $\mathrm{Co}$ in plants [28]. AtHMA4, knockout mutants show more sensitivity to $\mathrm{Cd}$ and $\mathrm{Zn}$ than the wild type [29,30]. In O. sativa, OsHMA1 is suspected to be involved in Zn transport, whereas OsHMA3 only transports $\mathrm{Cd}$ and acts as a $\mathrm{Cd}$ isolation agent in root cell vacuoles $[23,31,32]$.

In addition, the $H M A$ gene family has been identified in other species of plants including barley, Populus trichocarpa, and Brassica napus [33-35]. To date, researchers working on S. plumbizincicola have revealed that SpHMA1 located in the chloroplast membrane acting as a chloroplast $\mathrm{Cd}$ exporter and protecting photosynthesis by preventing the accumulation of $\mathrm{Cd}$ in the chloroplast, SpHMA2 was located in plasma membrane and its heterologous expression in yeast increased $\mathrm{Cd}$ resistance. SpHMA3 localized in the tonoplast played a crucial part in $\mathrm{Cd}$ detoxification in young leaves and stems by sequestrating $\mathrm{Cd}$ into the vacuoles instead of directly regulating Cd accumulation [17,36,37]. Nevertheless, current studies on the HMA gene family of $S$. plumbizincicola are very limited. As such, the present study sets out to perform a genome-wide analysis, phylogenetic analysis, as well as ex- 
pressional analysis of the SpHMAs to provide a theoretical basis for further studies on the functions and molecular mechanisms of HMA genes in S. plumbizincicola.

\section{Results}

\subsection{Genome-Wide Analysis of the SpHMAs}

In this study, a total of $8 H M A$ genes were identified in S. plumbizincicola (Table S1). These genes were named SpHMA1-SpHMA8 based on phylogenetic relationships in order to be consistent with $H M A$ gene family members in S. plumbizincicola which were confirmed previously and their basic characteristic information is organized in Table 1 . The length of their deduced proteins ranged from 694 aa to 995 aa, with an average length of 859.875 aa (Table S2). The predicted isoelectric points of the HMA proteins are in the range of 5.55 (SpHMA1) to 8.67 (SpHMA5) and approximately $90 \%$ of them have a molecular weight above $80 \mathrm{KDa}$. All of the SpHMAs contain the conserved HMA motifs (DKTGT, GDGxNDxP, PxxK S/TGE, HP, and CPx/SPC) and there is basically no significant difference among them. Previous studies in SpHMA1, SpHMA2, and SpHMA3 have shown their subcellular localization is distributed in three different locations of chloroplast membrane, plastid membrane and tonoplast, respectively. Here we predicted the subcellular localizations of the rest of SpHMAs with the Plant-mPLoc software and found that all of them have a cell membrane localization.

Table 1. Characteristics of 8 SpHMAs identified in S. plumbizincicola.

\begin{tabular}{|c|c|c|c|c|c|c|c|c|c|c|c|c|c|}
\hline S.N. & Gene Name & Gene ID & Chr. No. & $\begin{array}{l}\text { Protein Length } \\
\text { (AA) }\end{array}$ & $\begin{array}{l}\mathrm{MW} \\
\text { (KDa) }\end{array}$ & PI & $\begin{array}{l}\text { Predict } \\
\text { Location }\end{array}$ & Motif & & & & & \\
\hline 1 & SpHMA1 & evm.model.000029F.120 & Chr11 & 841 & 91.75 & 8.67 & Chloroplast & TGE & SPC & DKTGT & $\mathrm{HP}$ & PEDK & GDGINDAP \\
\hline 2 & SpHMA2 & evm.model.000008F.259 & Chr18 & 771 & 82.22 & 7.17 & Cell membrane & TGE & CPC & DKTGT & $\mathrm{HP}$ & PEDK & GDGINDAP \\
\hline 3 & SpHMA3 & evm.model.000098F.40 & Chr03 & 805 & 86.87 & 5.7 & tonoplast & TGE & CPC & DKTGT & $\mathrm{HP}$ & PEDK & GDGINDAP \\
\hline 4 & SpHMA4 & evm.model.000053F.243.6 & Chro6 & 995 & 107.58 & 5.61 & Cell membrane & TGE & CPC & DKTGT & HP & PLGK & GDGINDSP \\
\hline 5 & SpHMA5 & evm.model.000076F.84 & Chro1 & 959 & 103.56 & 5.55 & Cell membrane & TGE & CPC & DKTGT & $\mathrm{HP}$ & PDQK & GDGINDSP \\
\hline 6 & SpHMA6 & evm.model.000022F.259 & Chr31 & 936 & 98.47 & 7.92 & Cell membrane & TGE & CPC & DKTGT & $\mathrm{HP}$ & PDEK & GDGINDAA \\
\hline 7 & SpHMA7 & evm.model.000000F.676 & Chro2 & 694 & 74.55 & 7.03 & Cell membrane & TGE & CPC & DKTGT & HP & PAGK & GDGINDSP \\
\hline 8 & SpHMA8 & evm.model.000024F.130 & Chr27 & 878 & 93.06 & 5.84 & Cell membrane & TGE & CPC & DKTGT & HP & PQQK & GDGINDAP \\
\hline
\end{tabular}

By mapping the location of $S p H M A$ genes in the S. plumbizincicola genome, we found that all the candidate $H M A$ gene family members were randomly distributed on different chromosomes and all of them primarily located at the two ends of the chromosomes except SpHMA7 (Figure 1).

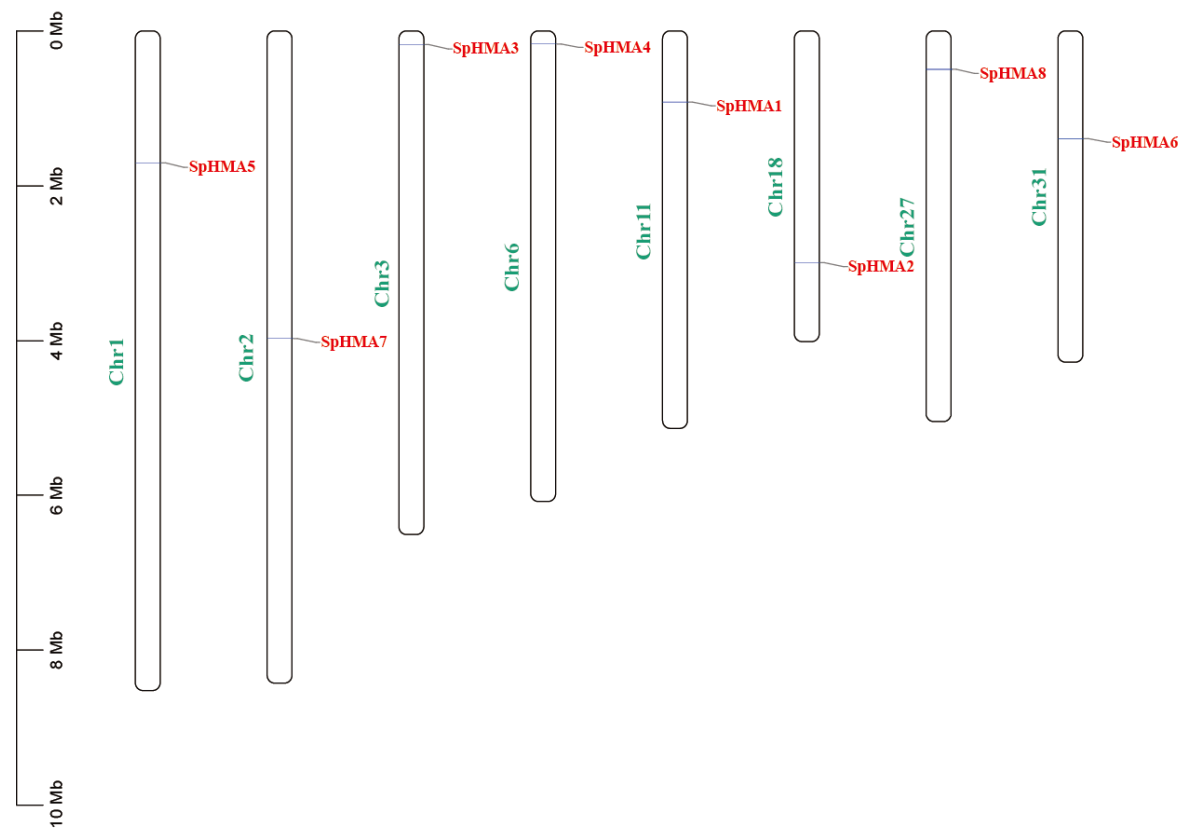

Figure 1. Chromosomal locations of SpHMA genes in S. plumbizincicola. Chromosome numbers are shown at the left of the bar with green font. $S p H M A$ genes are labeled at the right of the chromosomes with red font. Scale bar on the left indicates the chromosome lengths $(\mathrm{Mb})$. 


\subsection{Phylogenetic and Classification of the HMA Gene Family}

In order to figure out the evolutionary relationships of S. plumbizincicola HMA genes, we constructed a phylogenetic tree using the $H M A$ protein sequences from $A$. thaliana, $O$. sativa, Kalanchoe laciniata, and S. plumbizincicola (Figure 2). According to the phylogenetic analysis, the $H M A$ genes can be separated into two major groups, namely, $\mathrm{Zn} / \mathrm{Co} / \mathrm{Cd} / \mathrm{Pb}$ subgroup and $\mathrm{Cu} / \mathrm{Ag}$ subgroup. AtHMA1-AtHMA4, OsHMA1-OsHMA3, Kaladp0024s0591, Kaladp0515s0200, Kaladp0016s0349, and SpHMA1-SpHMA3 belong to the Zn/Co/Cd/Pb subgroup, while AtHMA5-AtHMA8, OsHMA4-OsHMA9, Kaladp0037s0087, Kaladp0022s0152, Kaladp0037s0088, Kaladp0023s0025, and SpHMA4-SpHMA8 are classified to the $\mathrm{Cu} / \mathrm{Ag}$ subgroup. The results of this study on the phylogenetic relationships of $H M A$ gene family members in A. thaliana, O. sativa are consistent with previous studies [23]. Remarkably, the relationship between S. plumbizincicola and K. laciniata was closer than that between S. plumbizincicola and other plants.
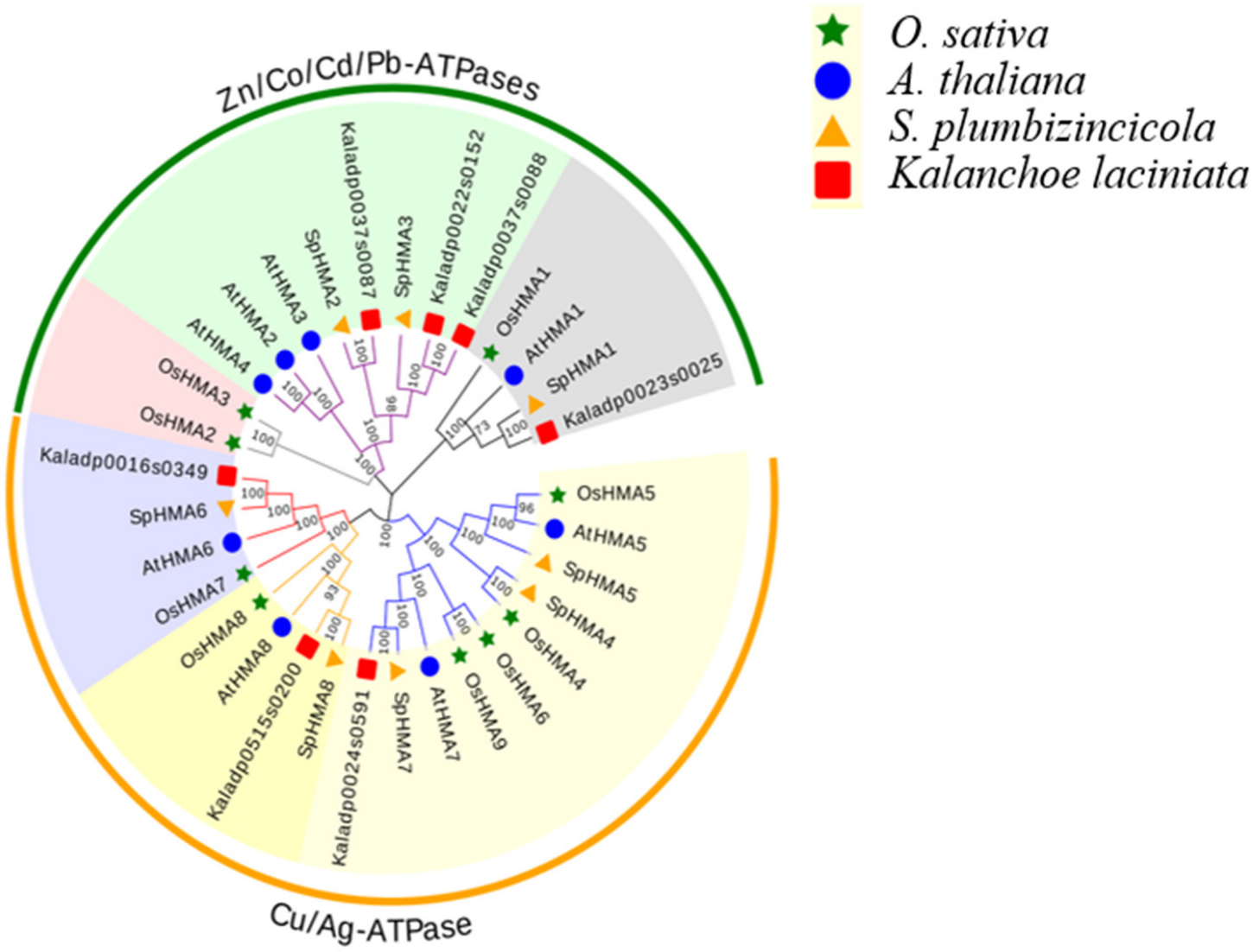

Figure 2. Phylogenetic analysis of HMA genes among A. thaliana, O. sativa, K. laciniata, S. plumbizincicola. MEGA 7.0 was used to construct a maximum likelihood (ML) phylogenetic tree with 1000 bootstrap replicates.

\subsection{Conserved Motifs and Gene Structure of SpHMAs}

Previous studies have revealed that the members of the HMA gene family were characterized by conserved motifs (DKTGT, GDGxNDxP, PxxK S/TGE, HP, and CPx/SPC). To further explore structural diversity and predict the potential function of them, 12 motifs were predicted with MEME Online software (Figure 3). Based on the results, we found that members of the same subclass mostly share the same motifs and members of different subclasses have slight differences. For instance, comparing with $\mathrm{Cu} / \mathrm{Ag}$-ATPases group, the members of $\mathrm{Zn} / \mathrm{Co} / \mathrm{Cd} / \mathrm{Pb}$ subgroup are missing several motifs. The motif 10 is missing in SpHMA1 while motifs 4, 9, and 10 are missing in SpHMA2 and motif 9 is missing in SpHMA2. The order of the motifs is basically the same regardless of the subclasses they belong to. 
The intron/exon organization, and the intron types and numbers can play an important role in the evolution of gene families, thus we detected the exon-intron structures of $S p H M A$ genes (Figure 3) and the result shows that the number of introns in each SpHMA gene range from 5 to 17 and $S p H M A$ genes except $S p H M A 7$ have a complete UTR region. The members in the same branch have a similar number of exons and introns, which suggests a conserved relationship in the process of evolution. For example, SpHMA6 and SpHMA8, located in the same clade, have 16 and 22 introns respectively, and SpHMA2 and SpHMA3 have 7 and 8 introns.

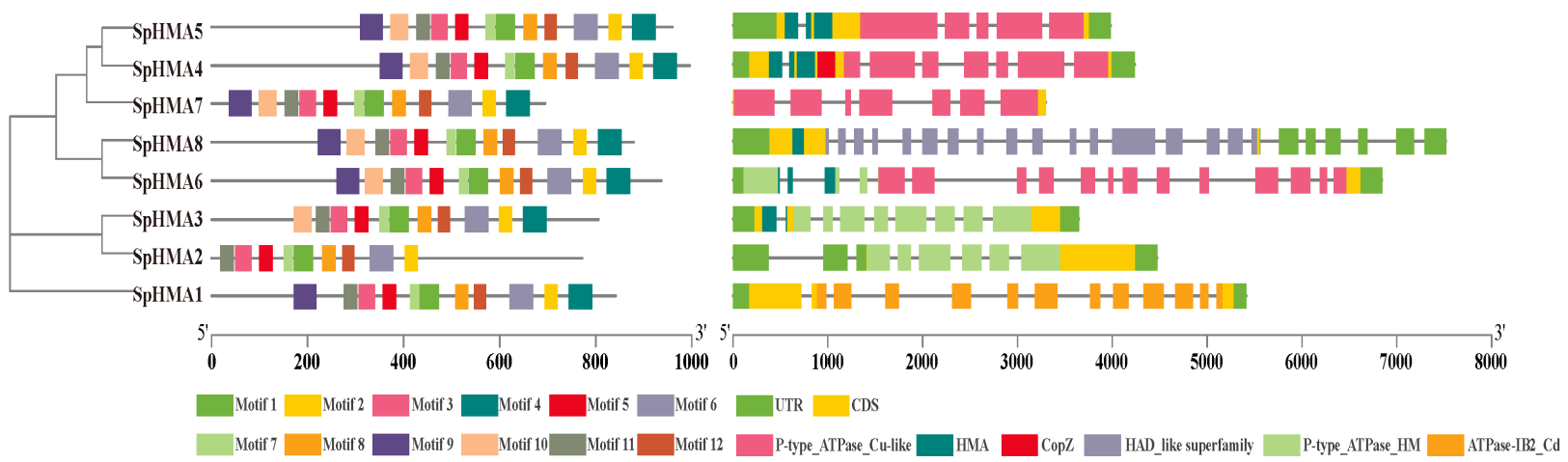

Figure 3. Phylogenetic relationships, motif compositions and gene structure of $H M A$ genes in S. plumbizincicola. (A) Phylogenetic relationships of 8 SpHMAs; (B) different motif compositions of SpHMAs were elucidated by MEME. The conserved motifs are represented by boxes with different colors; (C) gene structure and conserved domains of HMA genes in S. plumbizincicola.

Conserved domains are the core of genes and largely determine the function of them (Figure $3 C$ ). It was found in this study that all the SpHMA proteins contain domains unique to $H M A$ gene family members reported previous and the type of these domains form consistency with evolutionary relationship.

\subsection{Cis-Acting Elements in the Promoter Regions of SpHMA Genes}

Cis-acting elements are significant in gene transcription initiation regulation, due to the special functions of transcription factors DNA binding sites and other regulatory motifs. As an important gene family that can regulate heavy metal transport, the cisacting elements of the promoter of SpHMA genes are worth to be detected. We selected promoters with $2000 \mathrm{bp}$ region upstream of $5^{\prime}$ UTR to analyze with PlantCare (Figure 4). A total of 30 cis-regulatory elements were found in SpHMA genes. Generally, these cisacting elements can be divided into 3 categories, including cis-acting elements involved in growth and development, phytohormone responsiveness and biotic/abiotic stress. Most of the $S p H M A$ genes contain abiotic stress response elements, such as cis-acting regulatory element essential for the anaerobic induction (ARE) and box4 (part of the conserved DNA module involved in light response) elements. MBS (MYB binding site involved in drought inducibility) were found in promoter sequences of SpHMA2, SpHMA3, SpHMA5, SpHMA6 and LTR low-temperature response (LTR) elements were found in promoter sequences of SpHMA4, SpHMA5, SpHMA6, and SpHMA8. Moreover, phytohormone response elements were also detected in SpHMA genes. The CGTCA-motif and TGACG-motif (cis-acting regulatory element involved in the MeJA-responsiveness) were present in most promoter regions of $S p H M A$ genes. We found ABRE (cis-acting element involved in the abscisic acid responsiveness) in SpHMA1, SpHMA4, SpHMA5 and SpHMA8. These results suggest that the $S p H M A s$ may be regulated by various factors of stress, growth and development, and hormones. 


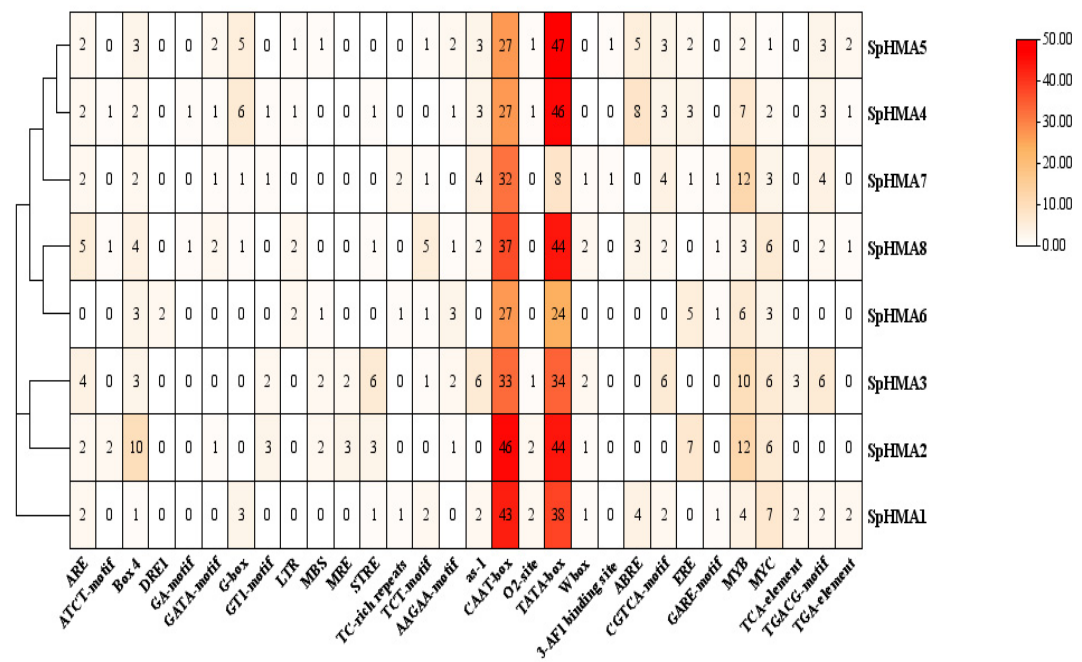

Figure 4. Cis-acting elements in promoters of SpHMA genes. All the predicted promoter region is $2000 \mathrm{bp}$. The different colors of grid represent the different number of promoters and the specific numbers are marked in it.

\subsection{Co-Expression Analysis of the HMA Genes in S. plumbizincicola}

Gene co-expression networks can be used to link genes of unknown function to certain biological processes [38]. In this study, we identified 5 hub genes, including SpHMA1, SpHMA2, SpHMA3, SpHMA4, SpHMA7, which were strongly associated with co-expressed genes. According to the network, there are 653 nodes and 792 edges (Figure 5), and basing on various functions, the edges were divided into 6 groups: binding process (405), catalytic activity (346), antioxidant activity (17), transporter activity (24), transcription factor activity (45), and response to stimulus (18) (Table S3). The co-expressed genes of most SpHMAs contained the above six groups of edges, suggesting that $S p H M A s$ may be responsive to plant stress-related stimuli. Among them, $\mathrm{SpHMA2}$ constitutes the largest module of the network and is associated with Cd stress [37].

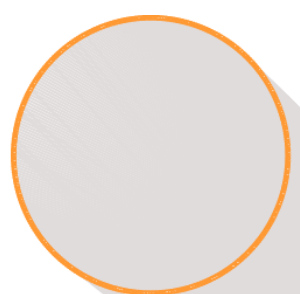

binding process
SpHMA1

SpHMA2

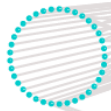

transcription factor activity<smiles>C1[C]2C[C]1C2</smiles>

antioxidant activity

\section{SpHMA3}

SpHMA4

\section{SpHMA7}

catalytic activity

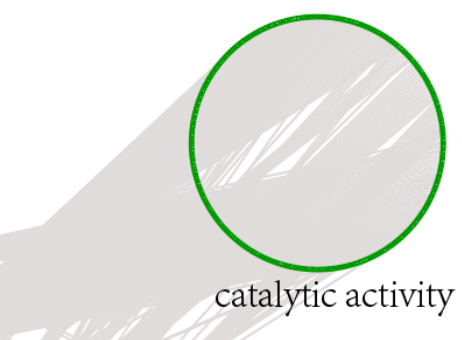

transporter activity

response to stimulus

Figure 5. Co-expression regulatory network of $S p H M A$ genes in S. plumbizincicola. Nodes representing individual genes and edges stand for significant co-expressions between genes. Genes involved in the same biological process are grouped together and filled with different colors: binding process (orange), catalytic activity (green), antioxidant activity (red), transporter activity (purple), transcription factor activity (blue) and response to stimulus (yellow). 


\subsection{Expression Profiles of SpHMA Genes in Various Tissues}

Transcriptome expression analysis can potentially reveal the tissue specificity of the $H M A$ gene family, and the general expressions were presented as a heat map in Figure 6. Based on the result, it was obvious that $S p H M A 2$ was significantly expressed in roots. The SpHMA4, SpHMA5, and SpHMA7 also showed higher root specificity compared with leaves and stems. Besides, SpHMA3 was expressed in roots, stems, and leaves, but a higher expression level was found in stems and leaves while SpHMA6 and SpHMA8 were preferentially expressed in leaves.

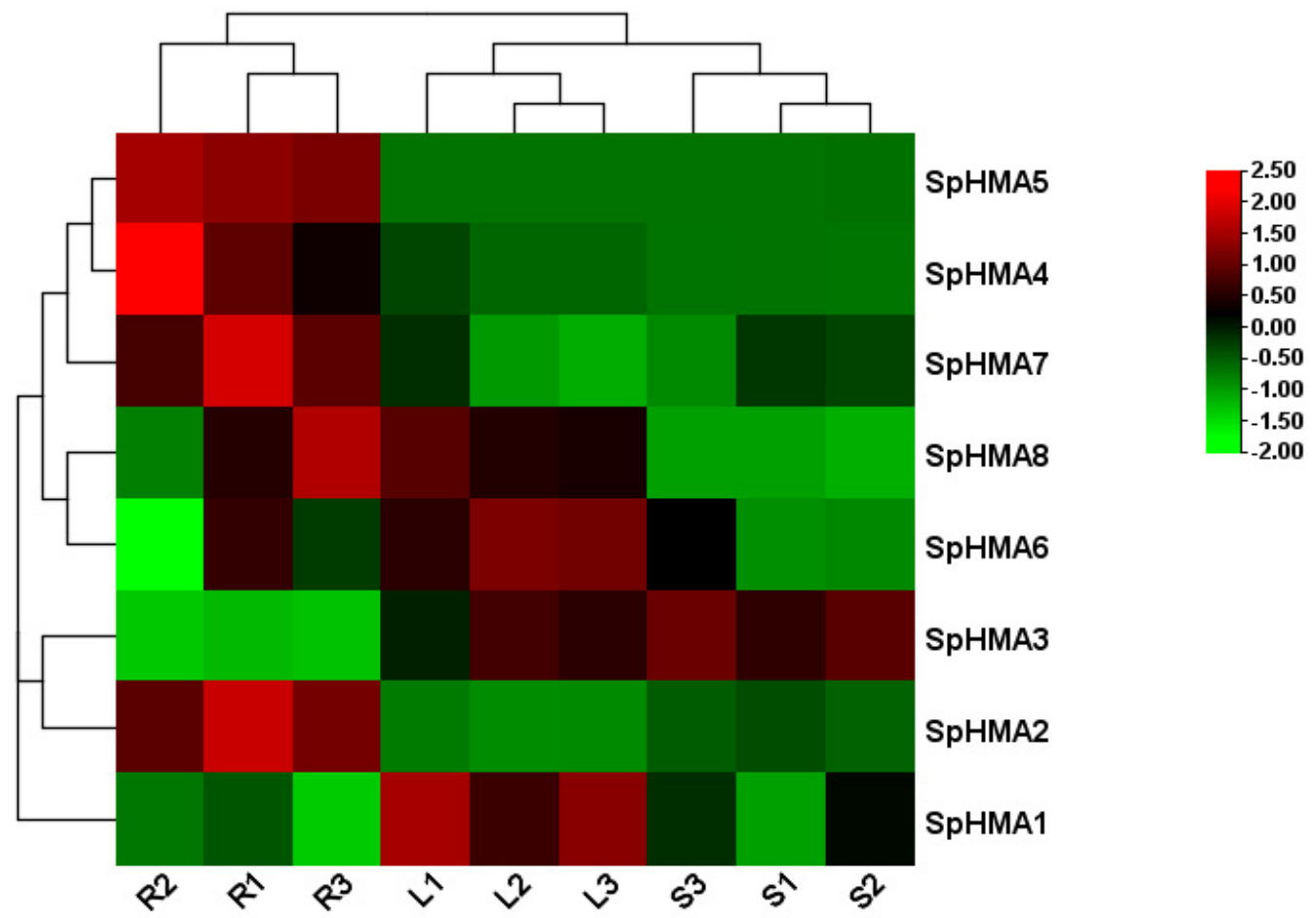

Figure 6. Expression pattern of 8 SpHMA genes in different tissues (R: roots; L: leaves; S: stems; 1, 2, and 3 are three biological replicates). The heat map was drawn using $\log 2$ transformed values, red and green represent high and low expression levels, respectively.

\section{7. qRT-PCR Expression Analysis of the SpHMAs}

The expression levels of SpHMAs were analyzed in different tissues under various treatment (Figure 7). Under Fe deficiency, the expression of SpHMA1, 2 and 3 appeared largely unaffected in various organizations, whereas the genes (SpHMA4, 5, 6 and 8) were found to be upregulated to varying degrees in roots (Figure 7A). The expression of $S p H-$ $M A s$ in the Mn deficiency condition was similar to that in the Fe deficiency treatment and most genes tend to be upregulated and then slowly recovered, instead of upregulated continuously. For instance, the SpHMA5 was significantly upregulated in stems at $12 \mathrm{~h}$ and subsequently returned to normal levels (Figure 7B). Under the Zn stress, the genes (SpHMA1, 2 and 3) seemed to be upregulated at different time points in various organizations, whereas the members of $\mathrm{Cu} / \mathrm{Ag}$ subgroup, mostly showed an unaffected or down-regulated trend, except the SpHMA4 and SpHMA7 (Figure 7C). Similarly, our results showed that $S p H M A 1$ and $S p H M A 2$ were significantly more highly expressed in roots in response to $\mathrm{Cd}$, which is consistent with previous studies. Notably, we observed that the expression level of SpHMA7 was also slightly upregulated in roots under Cd treatment and the upregulated trend was more obvious in leaves (Figure 7D). 

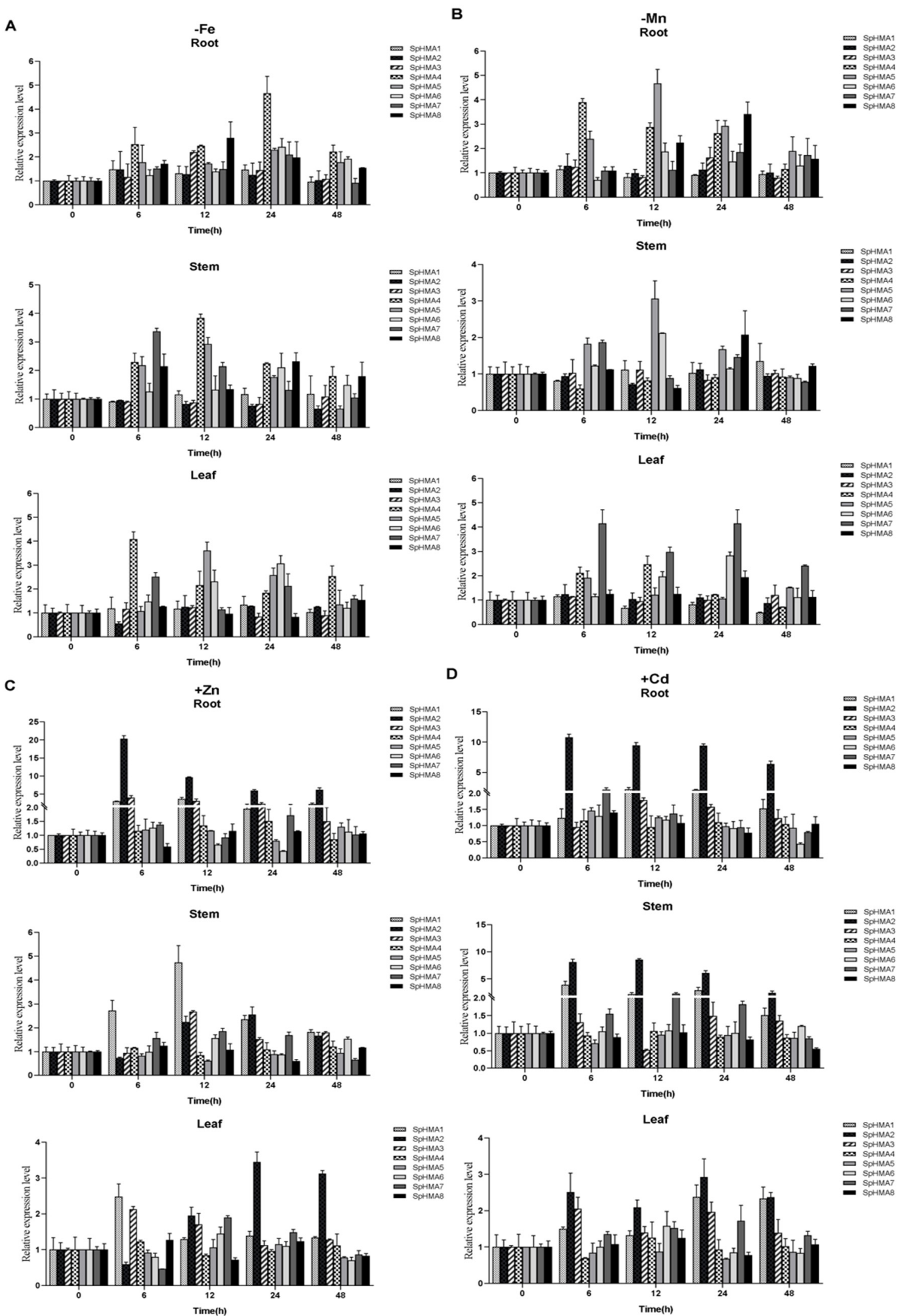

Figure 7. The qRT-PCR expression analysis of 8 SpHMAs under normal and stress condition. The stress treatment conditions were $\mathrm{Fe}$ (A), Mn (B) deficiency and $\mathrm{Zn}(\mathrm{C}), \mathrm{Cd}(\mathrm{D})$ excess, respectively. The expression levels of untreated $(0 \mathrm{~h})$ group were set to 1 as the control. Error bars were derived from three replicates of each experiment. 


\subsection{Heterologous Expression of SpHMA7 in Yeast}

Combined with the above qRT-PCR experimental results, the $S p H M A 7$ was selected to be overexpressed in yeast cells exposed to Cd stress. We cloned the SpHMA7 with a total length of $2085 \mathrm{bp}$ and successfully constructed the heterologous expression vector. The yeast strains expressing SpHMA7 were presented to be more sensitive to $30 \mu \mathrm{MCdCl}_{2}$ compared with the empty vector (Figure $8 \mathrm{~A}$ ). According to the results of growth curves, the growth inhibition of SpHMA7 under Cd stress was more severe, which further confirms the above results (Figure 8B). These results altogether indicated that $S p H M A 7$ may prevent the efflux of $\mathrm{Cd}$ by some means, and the specific mechanism needs to be further explored.

A

Control

\section{$30 \mu \mathrm{M} \mathrm{CdCl}_{2}$}

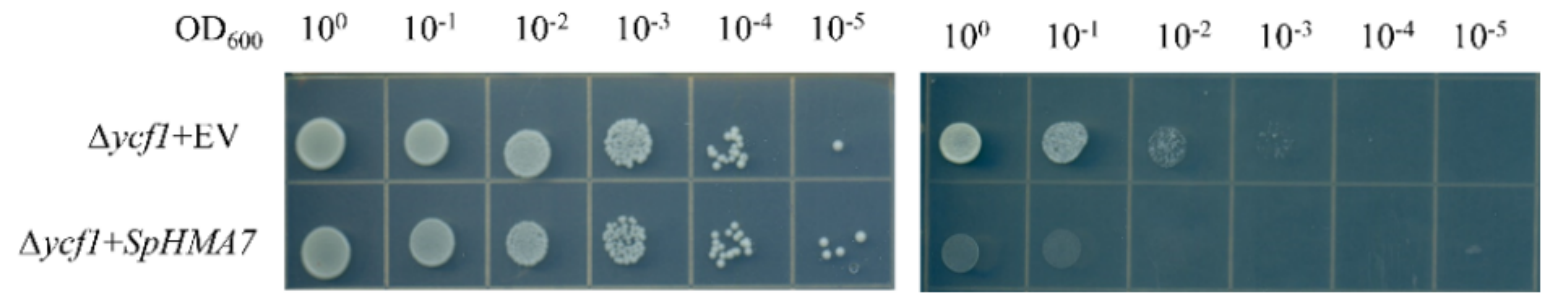

B

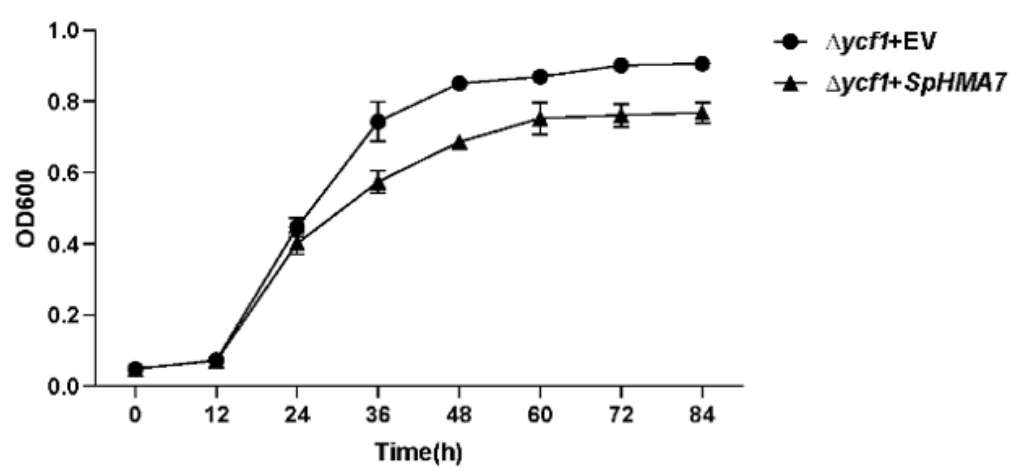

Figure 8. Effects of the overexpression of $S p H M A 7$ in yeast. (A) the growth of $\triangle y c f 1$ yeast mutants transformed with the empty vector pYES2.0 and SpHMA7; (B) growth curves of SpHMA7 and the control heterologously expressed in the strains of yeast in SG-U liquid medium treated with $30 \mu \mathrm{M}$ $\mathrm{CdCl}_{2}$.

\section{Discussion}

The heavy-metal ATPase plays an important role in plants heavy metal transport as a transmembrane transporter [39]. Since S. plumbizincicola tends to grow in mining areas rich in heavy metals and shows an excellent heavy metal resistance, we thought it might contain a great many members of the $H M A$ gene family, but we detected only eight members [40]. In the phylogenetic tree, these $H M A$ genes are divided into two subgroups, among which, of the same genus S. plumbizincicola and K. laciniata, whose genome data have been published, are more closely related. This suggests that the HMA gene family is relatively conserved in the family Crassulaceae, and in other words the existing $H M A$ members can play an important role. Further analysis also revealed that the HMA gene family is well-conserved and still contains some functional conserved sites such as DKTGT, GDGxNDxP, PxxK, TGE, HP, and CPC during the evolution of the S. plumbizincicola genome. However, these sites can be mutated in individual genes, and these changes may lead to the diversity of gene functions. For instance, CPC was an important metal binding sites and even found to be part of the $\mathrm{Cd}^{2+}$ transport sites, here in SpHMA1 protein sequence, it changes to SPC [41]. In addition, we also found other conservative motifs in SpHMAs, such as Motif 9 and Motif 10, whose function is unknown and needs further study. 
Subcellular localization is often closely related to the protein function, and here we predicted subcellular localization directly from the SpHMAs protein sequences and found that almost all the SpHMAs were predicted to be localized to the cell membrane except SpHMA1 and SpHMA3, which were confirmed to be located in chloroplast and tonoplast, respectively [42]. From a phylogenetic perspective, SpHMA1-3 belong to the $\mathrm{Zn} / \mathrm{Co} / \mathrm{Cd} / \mathrm{Pb}$-ATPases group, among which, SpHMA2 has a cell membrane localization. The results showed that subcellular localization of different subfamily members can be different, and the same subfamily members are also not share the same subcellular localization completely, suggesting that homologous genes may also play different roles. Of course, the exact location must be verified by specific experiments.

Most of the previous studies on members of the SpHMA gene family were focused on heavy metal stress, SpHMA1 has been identified as a $\mathrm{Cd}$ transporter for exporting $\mathrm{Cd}$ from the chloroplasts to the cytoplasm, SpHMA2 were identified as candidate Cd transport genes, and $S p H M A 3$ functions to transport Cd from the cytoplasm into the vacuoles $[37,43,44]$. Therefore, we used bioinformatics methods to predict and analyze cis-acting elements of all candidate SpHMAs promoters, and constructed the co-expression networks. The promoter analysis showed that most members of the $H M A$ gene family contained elements related to biotic/abiotic stress and the co-expression analysis also confirmed its role in stimulus and abiotic responses. These results conformably proved that $S p H M A s$ might play a crucial role in plant abiotic stress.

To better understand the potential functions of SpHMA genes, we studied the expression pattern of SpHMAs in different tissues using RNA-seq data and the result showed that most $S p H M A s$ had tissue expression specificity. The SpHMA5 has the highest expression levels in roots and almost no expression in stems and leaves. Moreover, the SpHMA3 is highly expressed in the stems and leaves, which is consistent with previous studies [17]. To further verify the expression of SpHMA gene obtained from RNA-seq data, qRT-PCR experiments were carried out with three different organizations (roots, stems, and leaves) under different treatments, including $50 \mu \mathrm{M} \mathrm{CdCl}_{2}, 100 \mu \mathrm{M} \mathrm{ZnSO}_{4}$, and Fe/Mn deficiency. It has been confirmed that AtHMA1 and OsHMA1 are involved in $\mathrm{Zn}$ and $\mathrm{Cd}$ transport and $S p H M A 1$ functions as a chloroplast $\mathrm{Cd}$ exporter [45]. AtHMA3 and OsHMA3 can transport $\mathrm{Cd}$ and excess $\mathrm{Zn}$ into the vacuoles, and $S p H M A 3$ plays an important role in $\mathrm{Cd}$ detoxification in the way of sequestrating $\mathrm{Cd}$ into the vacuoles, instead of directly regulating $\mathrm{Cd}$ hyperaccumulation for detoxification [46]. In this study, we found that both the expression of SpHMA1 and SpHMA3 were upregulated under Zn treatment, suggesting that they may also be involved in $\mathrm{Zn}$ transport. AtHMA2 was found to export $\mathrm{Zn}$ and $\mathrm{Cd}$ in the vascular tissues for root-to-shoot transportation and the SpHMA2 was recently discovered to play a similar role in Cd transport [47]. Here the results of qRT-PCR indicated that it can also be induced by other metals. AtHMA4 belongs to the $\mathrm{Zn} / \mathrm{Co} / \mathrm{Cd} / \mathrm{Pb}$ subclass in $A$. thaliana, which is related to the effluence of $\mathrm{Cd}$. While $S p H M A 4$ in this study belongs to the $\mathrm{Cu} / \mathrm{Ag}$ subclass, it may be related to Fe transport [48]. AtHMA5 participates in $\mathrm{Cu}$ detoxification and OsHMA5 is involved in xylem loading of $\mathrm{Cu}$. AtHMA6 (PAA1) and AtHMA8 (PAA2) are responsible for the transporting of $\mathrm{Cu}$ ions across the chloroplast envelope and thylakoids [49]. Our data suggested that the expression levels of the genes (SpHMA4, 5, 6, and 8) were not induced by $\mathrm{Cd}$ and $\mathrm{Zn}$, but in response to $\mathrm{Mn}$ and Fe to some extent. Specially, the expression level of SpHMA7 was slightly upregulated in stems and leaves in $\mathrm{Cd}$ treatment, whereas, the expression was firstly upregulated and subsequently down-regulated in roots.

In view of the results of the co-expression regulatory network and qRT-PCR experiments, we selected the hub gene, $S p H M A 7$, for yeast heterologous expression assays to explore whether it can transport $\mathrm{Cd}$. Recent studies have found that SpHMA2, belonging to the $\mathrm{Zn} / \mathrm{Co} / \mathrm{Cd} / \mathrm{Pb}$-ATPases group, which has a cell membrane location, showed weak $\mathrm{Cd}$ accumulation in yeast [37]. In this study, SpHMA7, the Cu/Ag subgroup member, which was predicted to be located in the cell membrane appeared to be sensitive to Cd compared with the control in yeast. In the above qRT-PCR experiment, SpHMA7 showed signs of 
up-regulation in roots, stems and leaves, suggesting its involvement in Cd stress response. It was speculated that $\mathrm{Cd}$ may occupy $\mathrm{Cu}^{2+}$ transport (SpHMA7) to promote the transport of Cd into cytoplasm.

\section{Conclusions}

In this study, we detected 8 HMA members in S. plumbizincicola which were divided into two subgroups according to phylogenetic relationship. The analysis of gene characterization, phylogenetic relationship, and biological function suggested that the SpHMAs are conservative during the evolution of $S$. plumbizincicola and play an important role in abiotic stress. The expression profiling of the SpHMAs presented tissue specificity under different metal stress. Heterologous expression of $S p H M A 7$ in yeast showed sensitivity to Cd stress. These results will be beneficial for further analysis of the mechanism of stress resistance of HMAs in S. plumbizincicola.

\section{Materials and Methods}

\subsection{Plant Materials and Treatments}

S. plumbizincicola used in this study was obtained from an old $\mathrm{Pb} / \mathrm{Zn}$ mine in Quzhou City, Zhejiang Province, China and then cultivated in an artificial climate chamber at $25{ }^{\circ} \mathrm{C}$ (16 h light, $8 \mathrm{~h}$ dark). The seedlings from a single genotype were water-cultivated initially in one-eighth-strength Hoagland nutrient solution and increased to half-strength after 3 days [50]. For about 1-month cultivation, the seedlings were treated with $50 \mu \mathrm{M} \mathrm{CdCl}_{2}$, $100 \mu \mathrm{M} \mathrm{ZnSO}_{4}, \mathrm{Fe} / \mathrm{Mn}$ deficiency and samples in the form of roots, stems and leaves were collected at $0,6,12,24$ and $48 \mathrm{~h}$ with three biological duplications. All the samples were immediately stored at $-80{ }^{\circ} \mathrm{C}$ for subsequent analysis.

\subsection{Identification and Sequence Analysis of HMA Genes in S. plumbizincicola}

The whole genome sequences of S. plumbizincicola were obtained from Zhuo's lab (unpublished), while the protein sequences of HMAs in the model plants $A$. thaliana and O. sativa were downloaded from Tair (https: / / www.arabidopsis.org/, accessed on 3 March 2021) and rgap (http: / / rice.uga.edu/, accessed on 4 March 2021), respectively. To identify the members of the HMA gene family in $S$. plumbizincicola, two strategies were applied using the above sequences. First, the eight known $H M A$ genes from $A$. thaliana were used as queries to carry out local BLASTp searches in the S. plumbizincicola Database with a cutoff e-value of $1 \times 10^{-10}$ Then the SMART (http:/ / smart.embl-heidelberg.de/, accessed on 13 March 2021) and PFAM (http:/ / pfam.xfam.org/, accessed on 13 March 2021) were used to check the candidate sequences that contained the conserved domains belonging to the HMA gene family. Second, a hidden Markov Model (PF00403) was obtained from the Pfam database (http:/ / pfam.xfam.org/, accessed on 13 March 2021) to search putative HMA genes from $S$. plumbizincicola with default thresholds. Finally, we manually deleted sequences that lacked conserved sequence motifs.

The molecular weight (MW) and isoelectric point (pI) of each HMA protein were calculated by ExPaSy (https:/ / www.expasy.org/resources/protparam, accessed on 15 March 2021), and Plant-mPLoc (http:/ / www.csbio.sjtu.edu.cn/bioinf/plant-multi/\#, accessed on 15 March 2021) was employed to forecast their subcellular localization. The chromosomal location of S. plumbizincicola HMA genes were obtained and mapped by the TBtools software (https: / / github.com/CJ-Chen/TBtools, accessed on 15 March 2021).

\subsection{Exon-Intron Structure, Motif Analysis and Promoter Element Analysis}

We employed the online program Gene Structure Display Server [51] to generate the exon/intron organization of HMA genes and MEME (http:/ / meme.sdsc.edu, accessed on 18 March 2021) was used to identify the motifs with a maximum motif number of 12. To identify the cis-acting elements of 8 SpHMA genes in the 2000 bp region upstream of $5^{\prime}$ untranslated region, the online software PlantCARE (http:/ / bioinformatics.psb.ugent. 
be/webtools/plantcare/html/, accessed on 17 March 2021) was utilized. All results were visualized using the TBtools software.

\subsection{Phylogenetic Analysis}

To study the phylogenetic relationship among HMA genes in S. plumbizincicola, the HMA amino acid sequences from A. thaliana, O. sativa and K. laciniata were downloaded from public databases and then all of them were aligned by MUSCLE and MEGA 7.0 was used to construct a maximum likelihood (ML) phylogenetic tree with 1000 bootstrap replicates. The evolutionary tree was finally visualized using the online tool Evolview (https:/ / evolgenius.info/ / evolview-v2/\#login, accessed on 18 March 2021).

\subsection{RNA Isolation and Expression Analysis}

The total RNA was isolated from roots, stems, and leaves using the Tiangen RNAprep plant kit (Tiangen, Beijing, China). First-strand cDNA synthesis was carried out with the PrimeScript ${ }^{\mathrm{TM}}$ RT reagent kit (Perfect Real Time; Takara, Dalian, China) and stored at $-20^{\circ} \mathrm{C}$ after diluting five times. To explore the expression of $S p H M A$ genes, we firstly extracted the expression profiles of $8 \mathrm{SpHMA}$ genes in different tissues with 3 biological repetitions from transcriptome data and quantitative real-time PCR (qRT-PCR) was subsequently performed using SYBR ${ }^{\circledR}$ Premix ExTaq ${ }^{\mathrm{TM}}$ reagent (TaKaRa, Dalian, China) with an amplification

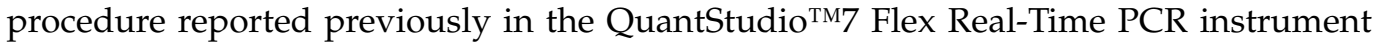
(Applied Biosystems, Foster City, California, United States ) to study the expression of genes describe above (5.1. Plant materials and Treatments). All specific primers were designed by Primer Premier 5.0 and the details are shown in Table 2. A total of $20 \mu \mathrm{L}$ reaction volume was used, including $10 \mu \mathrm{L} \mathrm{SYBR}^{\circledR}$ Premix Ex Taq ${ }^{\mathrm{TM}}(2 \times), 0.4 \mu \mathrm{L}$ gene-

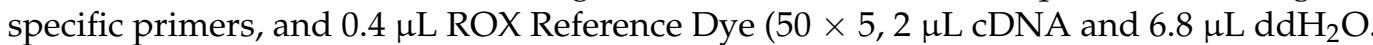
Each sample was performed with three technical replicates to ensure the reliability of the results. Finally, we calculated the gene expression by the $2^{-\Delta \Delta C T}$ method and selected SpUBC9 as the reference gene.

Table 2. Primers used in CDS full-length cloning, yeast heterologous expression vector recombining and qRT-PCR.

\begin{tabular}{ccc}
\hline Primer Name & Primer Sequence $\mathbf{( 5}^{\prime} \mathbf{- 3}^{\prime} \mathbf{)}$ & Primer Length (bp) \\
\hline SpHMA7-F & ATGCAGCTTCCAGTCATATTCA & 22 \\
SpHMA7-R & TTACTCTACAGTTATTTCAAGAATG & 25 \\
SpHMA7.pyes2-F & tcactatagggaatattaATGCAGCTTCCAGTCATATTCA & 40 \\
SpHMA7.pyes2-R & gatgcggcctctagTTACTCTACAGTTATTTCAAGAATG & 40 \\
SpUBC9-F & TGGCGTCGAAAAGGATTCTGA & 21 \\
SpUBC9-F & CCTTCGGTGGCTTGAATGGATA & 22 \\
qRT.SpHMA1-F & TGCTGCTGCTTGTCCTTACT & 20 \\
qRT.SpHMA1-R & AGACGCAAAGGCAGCCATAG & 22 \\
qRT.SpHMA2-F & GTGGCTGTAATCCCTGCTGT & 20 \\
qRT.SpHMA2-R & GATGTGGCCGCCTTTGAAAG & 21 \\
qRT.SpHMA3-F & TAAAATGGGTGGCTGTGGCT & 21 \\
qRT.SpHMA3-R & AACTGCCATGATTGCCAGGA & 21 \\
qRT.SpHMA4-F & TTATGGTGTCACCGCTGCAA & 20 \\
qRT.SpHMA4-R & TCAAACCCTGCATCCTCCAC & 20 \\
qRT.SpHMA5-F & GTTCGGATCGCTAACGTTGC & 20 \\
qRT.SpHMA5-R & TCAGCTCAGCTTCGAAACCA & 20 \\
qRT.SpHMA6-F & CAGAGGTGTTGCTGCTGGTA & 20 \\
qRT.SpHMA6-R & GCTGAAGACACTTGCGGTTG & 20 \\
qRT.SpHMA7-F & GTTGATCGAGCTTTCACCCG & 20 \\
qRT.SpHMA7-R & TGTCACCGGGTTGGATCAAT & 20 \\
qRT.SpHMA8-F & CGAAGAGACGTGTTTCGGGA & 20 \\
qRT.SpHMA8-R & CACAGCACAATGCCACCAAA & \\
\hline
\end{tabular}




\subsection{Co-Expression Network Construction}

The co-expression relationships of 5 selected genes were extracted from the transcriptome dataset of S. plumbizincicola [52] and the GO annotation information was obtained from the online platform (http:/ / www.omicshare.com/tools/Home/Soft/osgo, accessed on 28 September 2021). Eventually, a co-expression network was constructed and visualized using the Cytoscape software.

\subsection{Cloning and Construction of Expression Vectors}

For further study the functions of $H M A$ genes, we cloned the full length of SpHMA7 with KOD-Fx DNA Polymerase (Toyobo, Japan) and digested the plasmid of vector pYES2.0 with Hind III and XbaI (NEB, Nanjing, China). The purified PCR products were then cloned into the vector using ClonExpress II One Step Cloning Kit (Vazyme, Nanjing, China). Positive clones were selected and sequenced to ensure the successful construction of recombinant vector. Primers used in the process above were showed in Table 2.

\subsection{Yeast Expression Experiment}

To explore the $\mathrm{Cd}$ tolerance of $H M A$ in yeast, the recombinant plasmids pYES2.0SpHMA7 and empty pYES2.0 vector (control) were transformed into Cd-sensitive mutant yeast strain $\Delta y c f 1$ by the lithium acetate method [53]. Transformed yeast cells were cultivated in fluid nutrient medium with synthetic galactose-uracil (SG-U) until reaching the same $\mathrm{OD}_{600}$. The cells were spotted on SG-U agar plates supplemented with 0 and $30 \mu \mathrm{M}$ $\mathrm{CdCl}_{2}$ for about three days at $28^{\circ} \mathrm{C}$ in an incubator after gradient dilution $\left(\mathrm{OD}_{600}=10^{-0}\right.$, $10^{-1}, 10^{-2}, 10^{-3}, 10^{-4}$, and $10^{-5}$ ). Furthermore, the relative growth of transformants was determined in the way of measuring the optical density at $600 \mathrm{~nm}$ every $12 \mathrm{~h}$.

Supplementary Materials: The following supporting information can be downloaded at: https:// www.mdpi.com/article/10.3390/plants11020215/s1, Table S1: detailed information of gene sequence of SpHMAs; Table S2: detailed information of protein sequence of SpHMAs; Table S3: annotation of edges connected with hub SpHMAs.

Author Contributions: X.K. and R.Z. conceived and designed the experiments; Data curation, Q.H. and S.L.; Formal analysis, Q.H. and Y.Z.; Investigation, Q.H., M.Y., and Z.L.; Software, Z.L.; Validation, Q.H. and W.Q.; Writing—original draft, Q.H. and W.Q.; Writing—review and editing, W.Q. and R.Z. All authors have read and agreed to the published version of the manuscript.

Funding: This work was supported by the National Nonprofit Institute Research Grant of CAF (No. CAFYBB2019SZ001 RISFZ-2021-01 and CAFYBB2020SY016).

Institutional Review Board Statement: Not applicable.

Informed Consent Statement: Not applicable.

Conflicts of Interest: The authors declare that the study was conducted in the absence of any commercial or financial relationship that could be construed as a potential conflict of interest.

\section{References}

1. Adimalla, N.; Chen, J.; Qian, H. Spatial characteristics of heavy metal contamination and potential human health risk assessment of urban soils: A case study from an urban region of South India. Ecotoxicol. Environ. Saf. 2020, 194, 110406. [CrossRef]

2. Baker, A.J.; Brooks, R. Terrestrial higher plants which hyperaccumulate metallic elements. A review of their distribution, ecology and phytochemistry. Biorecovery 1989, 1, 81-126.

3. Pedron, T.; Segura, F.R.; da Silva, F.F.; de Souza, A.L.; Maltez, H.F.; Batista, B.L. Essential and non-essential elements in Brazilian infant food and other rice-based products frequently consumed by children and celiac population. J. Food Compos. Anal. 2016, 49, 78-86. [CrossRef]

4. Ali, H.; Khan, E. Trophic transfer, bioaccumulation, and biomagnification of non-essential hazardous heavy metals and metalloids in food chains/webs-Concepts and implications for wildlife and human health. Hum. Ecol. Risk Assess. 2019, 25, 1353-1376. [CrossRef]

5. Halder, D.; Saha, J.K.; Biswas, A. Accumulation of essential and non-essential trace elements in rice grain: Possible health impacts on rice consumers in West Bengal, India. Sci. Total Environ. 2020, 706, 135944. [CrossRef] [PubMed] 
6. Huang, Y.; Hao, X.; Lei, M.; Tie, B. The remediation technology and remediation practice of heavy metals-contaminated soil. J. Agro-Environ. Sci. 2013, 32, 409-417.

7. Cunningham, S.D.; Ow, D.W. Promises and Prospects of Phytoremediation. Plant Physiol. 1996, 110, 715-719. [CrossRef] [PubMed]

8. Awa, S.H.; Hadibarata, T. Removal of heavy metals in contaminated soil by phytoremediation mechanism: A review. Water Air Soil Pollut. 2020, 231, 1-15. [CrossRef]

9. Sytar, O.; Ghosh, S.; Malinska, H.; Zivcak, M.; Brestic, M. Physiological and molecular mechanisms of metal accumulation in hyperaccumulator plants. Physiol. Plant. 2021, 173, 148-166. [CrossRef]

10. Verbruggen, N.; Juraniec, M.; Baliardini, C.; Meyer, C.-L. Tolerance to cadmium in plants: The special case of hyperaccumulators. BioMetals 2013, 26, 633-638. [CrossRef]

11. Wu, L.H.; Liu, Y.J.; Zhou, S.B.; Guo, F.G.; Bi, D.; Guo, X.H.; Baker, A.J.M.; Smith, J.A.C.; Luo, Y.M. Sedum plumbizincicola X.H. Guo et S.B. Zhou ex L.H. Wu (Crassulaceae): A new species from Zhejiang Province, China. Plant Syst. Evol. 2013, 299, 487-498. [CrossRef]

12. Song, W.; Wang, J.; Zhai, L.; Ge, L.; Hao, S.; Shi, L.; Lian, C.; Chen, C.; Shen, Z.; Chen, Y. A meta-analysis about the accumulation of heavy metals uptake by Sedum alfredii and Sedum plumbizincicola in contaminated soil. Int. J. Phytoremed. 2021. [CrossRef]

13. Sun, L.; Cao, X.; Tan, C.; Deng, Y.; Cai, R.; Peng, X.; Bai, J. Analysis of the effect of cadmium stress on root exudates of Sedum plumbizincicola based on metabolomics. Ecotoxicol. Environ. Saf. 2020, 205, 111152. [CrossRef] [PubMed]

14. Huang, R.; Dong, M.; Mao, P.; Zhuang, P.; Paz-Ferreiro, J.; Li, Y.; Li, Y.; Hu, X.; Netherway, P.; Li, Z. Evaluation of phytoremediation potential of five Cd (hyper) accumulators in two Cd contaminated soils. Sci. Total Environ. 2020, 721, 137581. [CrossRef]

15. Wong, C.K.E.; Cobbett, C.S. HMA P-type ATPases are the major mechanism for root-to-shoot Cd translocation in Arabidopsis thaliana. New Phytol. 2009, 181, 71-78. [CrossRef]

16. Cao, D.; Zhang, H.; Wang, Y.; Zheng, L. Accumulation and Distribution Characteristics of Zinc and Cadmium in the Hyperaccumulator Plant Sedum plumbizincicola. Bull. Environ. Contam. Toxicol. 2014, 93, 171-176. [CrossRef] [PubMed]

17. Liu, H.; Zhao, H.; Wu, L.; Liu, A.; Zhao, F.J.; Xu, W. Heavy metal ATPase 3 (HMA3) confers cadmium hypertolerance on the cadmium/zinc hyperaccumulator Sedum plumbizincicola. New Phytol. 2017, 215, 687-698. [CrossRef]

18. Li, L.-Z.; Tu, C.; Wu, L.-H.; Peijnenburg, W.J.G.M.; Ebbs, S.; Luo, Y.-M. Pathways of root uptake and membrane transport of Cd ${ }^{2+}$ in the zinc/cadmium hyperaccumulating plant Sedum plumbizincicola. Environ. Toxicol. Chem. 2017, 36, 1038-1046. [CrossRef]

19. Fasani, E.; Manara, A.; Martini, F.; Furini, A.; DalCorso, G. The potential of genetic engineering of plants for the remediation of soils contaminated with heavy metals. Plant Cell Environ. 2018, 41, 1201-1232. [CrossRef] [PubMed]

20. Verbruggen, N.; Hermans, C.; Schat, H. Molecular mechanisms of metal hyperaccumulation in plants. New Phytol. 2009, 181, 759-776. [CrossRef]

21. Schat, H.; Llugany, M.; Bernhard, R. Metal-specific patterns of tolerance, uptake, and transport of heavy metals in hyperaccumulating and nonhyperaccumulating metallophytes. In Phytoremediation of Contaminated Soil and Water; CRC Press: Boca Raton, FL, USA, 2020; pp. 171-188.

22. Zeng, F.; Chen, G.; Chen, X.; Li, Q.; Wu, X.; Zhang, G.-P. Cadmium accumulation in plants: Insights from physiological/molecular mechanisms to evolutionary biology. Authorea Preprint 2020. [CrossRef]

23. Williams, L.E.; Mills, R.F. P1B-ATPases-An ancient family of transition metal pumps with diverse functions in plants. Trends Plant Sci. 2005, 10, 491-502. [CrossRef] [PubMed]

24. Axelsen, K.B.; Palmgren, M.G. Evolution of substrate specificities in the P-type ATPase superfamily. J. Mol. Evol. 1998, 46, 84-101. [CrossRef]

25. Smith, A.T.; Smith, K.P.; Rosenzweig, A.C. Diversity of the metal-transporting P 1B-type ATPases. J. Biol. Inorg. Chem. 2014, 19, 947-960. [CrossRef] [PubMed]

26. Axelsen, K.B.; Palmgren, M.G. Inventory of the superfamily of P-type ion pumps in Arabidopsis. Plant Physiol. 2001, 126, 696-706. [CrossRef] [PubMed]

27. Kim, Y.Y.; Choi, H.; Segami, S.; Cho, H.T.; Martinoia, E.; Maeshima, M.; Lee, Y. AtHMA1 contributes to the detoxification of excess Zn (II) in Arabidopsis. Plant J. 2009, 58, 737-753. [CrossRef] [PubMed]

28. Morel, M.; Crouzet, J.; Gravot, A.; Auroy, P.; Leonhardt, N.; Vavasseur, A.; Richaud, P. AtHMA3, a P1B-ATPase allowing $\mathrm{Cd} / \mathrm{Zn} / \mathrm{co} / \mathrm{Pb}$ vacuolar storage in Arabidopsis. Plant Physiol. 2009, 149, 894-904. [CrossRef] [PubMed]

29. Mills, R.F.; Francini, A.; da Rocha, P.S.F.; Baccarini, P.J.; Aylett, M.; Krijger, G.C.; Williams, L.E. The plant P1B-type ATPase AtHMA4 transports $\mathrm{Zn}$ and $\mathrm{Cd}$ and plays a role in detoxification of transition metals supplied at elevated levels. FEBS Lett. 2005, 579, 783-791. [CrossRef] [PubMed]

30. Verret, F.; Gravot, A.; Auroy, P.; Leonhardt, N.; David, P.; Nussaume, L.; Vavasseur, A.; Richaud, P. Overexpression of AtHMA4 enhances root-to-shoot translocation of zinc and cadmium and plant metal tolerance. FEBS Lett. 2004, 576, 306-312. [CrossRef]

31. Ueno, D.; Yamaji, N.; Kono, I.; Huang, C.F.; Ando, T.; Yano, M.; Ma, J.F. Gene limiting cadmium accumulation in rice. Proc. Natl. Acad. Sci. USA 2010, 107, 16500-16505. [CrossRef]

32. Miyadate, H.; Adachi, S.; Hiraizumi, A.; Tezuka, K.; Nakazawa, N.; Kawamoto, T.; Katou, K.; Kodama, I.; Sakurai, K.; Takahashi, H. OsHMA3, a P1B-type of ATPase affects root-to-shoot cadmium translocation in rice by mediating efflux into vacuoles. New Phytol. 2011, 189, 190-199. [CrossRef] [PubMed]

33. Fang, X.; Wang, L.; Deng, X.; Wang, P.; Ma, Q.; Nian, H.; Wang, Y.; Yang, C. Genome-wide characterization of soybean P 1B-ATPases gene family provides functional implications in cadmium responses. BMC Genom. 2016, 17, 376. [CrossRef] [PubMed] 
34. Li, D.; Xu, X.; Hu, X.; Liu, Q.; Wang, Z.; Zhang, H.; Wang, H.; Wei, M.; Wang, H.; Liu, H. Genome-wide analysis and heavy metal-induced expression profiling of the HMA gene family in Populus trichocarpa. Front. Plant Sci. 2015, 6, 1149. [CrossRef] [PubMed]

35. Li, N.; Xiao, H.; Sun, J.; Wang, S.; Wang, J.; Chang, P.; Zhou, X.; Lei, B.; Lu, K.; Luo, F. Genome-wide analysis and expression profiling of the HMA gene family in Brassica napus under cd stress. Plant Soil 2018, 426, 365-381. [CrossRef]

36. Zhao, H.; Wang, L.; Zhao, F.J.; Wu, L.; Liu, A.; Xu, W. SpHMA1 is a chloroplast cadmium exporter protecting photochemical reactions in the Cd hyperaccumulator Sedum plumbizincicola. Plant Cell Environ. 2019, 42, 1112-1124. [CrossRef] [PubMed]

37. Zhu, Y.; Qiu, W.; Li, Y.; Tan, J.; Han, X.; Wu, L.; Jiang, Y.; Deng, Z.; Wu, C.; Zhuo, R. Quantitative proteome analysis reveals changes of membrane transport proteins in Sedum plumbizincicola under cadmium stress. Chemosphere 2022, 287, 132302. [CrossRef]

38. Van Dam, S.; Vosa, U.; van der Graaf, A.; Franke, L.; de Magalhaes, J.P. Gene co-expression analysis for functional classification and gene-disease predictions. Brief Bioinform. 2018, 19, 575-592. [CrossRef]

39. Nosek, M.; Kaczmarczyk, A.; Jędrzejczyk, R.J.; Supel, P.; Kaszycki, P.; Miszalski, Z. Expression of genes involved in heavy metal trafficking in plants exposed to salinity stress and elevated Cd concentrations. Plants 2020, 9, 475. [CrossRef]

40. Zhang, Z.; Qiu, W.; Liu, W.; Han, X.; Wu, L.; Yu, M.; Qiu, X.; He, Z.; Li, H.; Zhuo, R. Genome-wide characterization of the hyperaccumulator Sedum alfredii F-box family under cadmium stress. Sci. Rep. 2021, 11, 3023. [CrossRef]

41. Bal, N.; Wu, C.C.; Catty, P.; Guillain, F.; Mintz, E. Cd ${ }^{2+}$ and the N-terminal metal-binding domain protect the putative membranous CPC motif of the $\mathrm{Cd}^{2+}$-ATPase of Listeria monocytogenes. Biochem. J. 2003, 369, 681-685. [CrossRef]

42. Yu, C.-S.; Chen, Y.-C.; Lu, C.-H.; Hwang, J.-K. Prediction of protein subcellular localization. Proteins 2006, 64, 643-651. [CrossRef] [PubMed]

43. Zhang, J.; Martinoia, E.; Lee, Y. Vacuolar transporters for cadmium and arsenic in plants and their applications in phytoremediation and crop development. Plant Cell Physiol. 2018, 59, 1317-1325. [CrossRef] [PubMed]

44. Wu, L.; Hu, P.; Li, Z.; Xu, W.; Zhou, T.; Zhong, D.; Luo, Y. Element case studies: Cadmium and zinc. In Agromining: Farming for Metals; Springer: Berlin/Heidelberg, Germany, 2021; pp. 453-469.

45. Takahashi, R.; Bashir, K.; Ishimaru, Y.; Nishizawa, N.K.; Nakanishi, H. The role of heavy-metal ATPases, HMAs, in zinc and cadmium transport in rice. Plant Signal. Behav. 2012, 7, 1605-1607. [CrossRef] [PubMed]

46. Haque, A.M.; Gohari, G.; EI-Shehawi, A.M.; Dutta, A.K.; Elseehy, M.M.; Kabir, A.H. Genome wide identification, characterization and expression profiles of heavy metal ATPase3 (HMA3) in plants. J. King Saud Univ. Sci. 2022, 34, 101730. [CrossRef]

47. Takahashi, R.; Ishimaru, Y.; Shimo, H.; Ogo, Y.; Senoura, T.; Nishizawa, N.K.; Nakanishi, H. The OsHMA2 transporter is involved in root-to-shoot translocation of Zn and Cd in rice. Plant Cell Environ. 2012, 35, 1948-1957. [CrossRef]

48. Chaudhary, K.; Jan, S.; Khan, S. Heavy metal ATPase (HMA2, HMA3, and HMA4) genes in hyperaccumulation mechanism of heavy metals. In Plant Metal Interaction; Elsevier: Amsterdam, The Netherlands, 2016; pp. 545-556.

49. Abdel-Ghany, S.E.; Müller-Moulé, P.; Niyogi, K.K.; Pilon, M.; Shikanai, T. Two P-type ATPases are required for copper delivery in Arabidopsis thaliana chloroplasts. Plant Cell 2005, 17, 1233-1251. [CrossRef]

50. Hoagland, D.R.; Arnon, D.I. The water-culture method for growing plants without soil. Calif. Agric. Exp. Stn. Circ. 1950, 347, 357-359.

51. Hu, B.; Jin, J.; Guo, A.-Y.; Zhang, H.; Luo, J.; Gao, G. GSDS 2.0: An upgraded gene feature visualization server. Bioinformatics 2015 31, 1296-1297. [CrossRef]

52. Han, X.; Yin, H.; Song, X.; Zhang, Y.; Liu, M.; Sang, J.; Jiang, J.; Li, J.; Zhuo, R. Integration of small RNA s, degradome and transcriptome sequencing in hyperaccumulator Sedum alfredii uncovers a complex regulatory network and provides insights into cadmium phytoremediation. Plant Biotechnol. J. 2016, 14, 1470-1483. [CrossRef]

53. Szczypka, M.S.; Wemmie, J.A.; Moye-Rowley, W.S.; Thiele, D.J. A yeast metal resistance protein similar to human cystic fibrosis transmembrane conductance regulator (CFTR) and multidrug resistance-associated protein. J. Biol. Chem. 1994, $269,22853-22857$. [CrossRef] 